\title{
ANALISIS KETERLAKSANAAN PROBLEM BASED LEARNING BERBANTUAN MULTIMEDIA PEMBELAJARAN LARUTAN ASAM BASA TERHADAP KETERAMPILAN MEMECAHKAN MASALAH
}

\author{
Dian Indah Lestari, M. Rusdi, Fatria Dewi \\ Program Studi Pendidikan Kimia, Fakultas Keguruan dan Ilmu Pendidikan Universitas Jambi \\ Email: dianindah2297@gmail.com
}

\begin{abstract}
This study aims to determine the extent of problem-based learning model implementation assisted instruction multimedia with the type of strategic performance problems in improving students' problem solving skills on acidic and alkaline materials. The approach used in this research is mixed approach (mix method) with a sequential exploratory model type (model sequence of discovery). The sampling technique is done by purposive sampling. The instrument of research is in the form of observation sheet implementation of problem-based learning model both from teachers and students and also student essay test. The correlation of problem-based learning model implementation with students' problem solving skill is sought with product moment. The implementation of problem-based learning model by teachers and students has been done according to the principle of problem-based learning model of each meeting. The implementation of problem-based learning model by students with average percentage of $88,44 \%$ and ability to solve student problem with average percentage of $69,02 \%$. The correlation of problem-based learning model implementation assisted instruction multimedia of acid-base solution with the problem solving skill is categorized by mediocre with average of 0.43. It can be concluded that the problem-based learning model assisted instruction multimedia acid-base learning in class XI MIA 1 SMA Islam Al-Falah Kota Jambi has been implemented well by teachers and students and also the problem solving skills of students have emerged.
\end{abstract}

Keywords: Problem Based Learning, Multimedia, Strategic Permofance, Problem Solving, Acid and Alkaline

\section{PENDAHULUAN}

Pendidikan sangat penting dalam rangka menumbuh kembangkan kualitas sumber daya manusia (SDM). Peningkatan kualitas sumber daya manusia ini dapat dilalui dengan proses pembelajaran yang menitikberatkan pada aktivitas siswa di kelas (Wiyani, 2013). Dimana siswa diharapkan secara aktif mengembangkan potensi dirinya untuk memiliki kekuatan spiritual keagamaan, pengendalian diri, kecerdasan, akhlak mulia, serta keterampilan yang diperlukan dirinya dan masyarakat sesuai dengan tujuan pendidikan yang tertuang dalam Undang-Undang Nomor 20 Tahun 2003 tentang Sistem Pendidikan Nasional.
Salah satu rencana strategi pendidikan nasional yaitu peningkatan efisiensi pengelolaan pendidikan yang mengarah pada penataan kurikulum berbasis kompetensi dan karakter. Kurikulum 2013 merupakan salah satunya, dalam implementasinya, guru dituntut profesional pembelajaran efektif dan bermakna (menyenangkan) menggunakan model pembelajaran yang sesuai dengan materi yang akan diajarkan. Dalam proses pembelajaran juga di tuntut menggunakan multimedia pembelajaran, guru dapat bertindak sebagai fasilitator dan pembimbing pembelajaran bagi siswa.

Pembelajaran dalam ilmu kimia membutuhkan lebih banyak keterampilan siswa 
baik itu secara psikis maupun fisik. Ilmu kimia adalah ilmu yang di temukan dan dikembangkan berdasarkan eksperimen yang merupakan jawaban atas pertanyaan apa, kenapa, dan mengapa serta gejala-gejala alam yang terjadi.

Asam dan basa merupakan bagian dari materi dalam pelajaran kimia SMA khususnya kelas XI dengan karakteristik materi berupa konsepkonsep yang ada dalam fakta kehidupan seharihari yang bersifat makroskopis, mikroskopis dan simbolik. Agar siswa dapat memahami konsep dasar asam dan basa dan kaitannya dengan kehidupan sehari-hari maka perlu disajikan dalam bentuk yang menarik sehingga siswa tidak hanya menghafal konsep melainkan mampu mengembang kemampuan berpikirnya dalam memecahkan masalah, sehingga memunculkan gagasan baru menurut pandangannya sendiri yang dirangkum dari konsep yang sudah ada.

Berdasarkan hasil observasi dan wawancara terhadap guru bidang kimia di SMA Islam AlFalah Kota Jambi pada tanggal 9 November 2017, proses pembelajaran guru menerapkan pembelajaran berbasis masalah dengan membawa siswa berpikir ke arah suatu permasalahan atau fakta dalam kehidupan seharihari agar siswa lebih mudah memahami materi yang dipelajarinya. Namun, siswa mengalami kesulitan memahami konsep dalam proses pembelajaran khususnya materi larutan asam dan basa, karena pada saat proses pembelajaran siswa hanya mengerti saat pembelajaran berlangsung hari itu saja, saat dilanjutkan pada hari selanjutnya siswa lupa mengenai materi yang telah dipelajari. Sehingga siswa hanya menerima pengetahuan materi yang makroskopis saja tanpa memahami karakteristik dari materi asam basa yang mikroskopis dan simbolik. Proses pembelajaran larutan asam dan basa ini guru terkadang menerapkan praktikum. Meskipun metode praktikum dilakukan dengan persiapan dari guru sudah bagus disertai prosedur yang lengkap serta didukung oleh laboratorium yang lengkap, masih banyak siswa yang belum memahami arti sesungguhnya dilakukannya praktikum, tanpa membayangkan berbagai hal yang berkaitan dengan permasalahan praktikum yang dilakukan untuk diselesaikan sendiri. Jadi, siswa cenderung memperoleh ranah kognitif saja tetapi kurang terampil dalam memecahkan masalah, interaksi sosial rendah, serta kegiatan belajar megajar kurang efisien. Fasilitas yang ada dikelas dan di laboratorium sudah lengkap, guru kurang memanfaatkan teknologi yang telah disediakan untuk proses pembelajaran. Guru terkadang hanya menampilkan video dari youtube dan menjelaskan materi menggunakan power point dalam pembelajaran.

Hal yang dapat dilakukan untuk mengatasi masalah tersebut adalah dengan melakukan pembaharuan dalam pembelajaran. Salah satunya menggunakan variasi model pembelajaran yang dilengkapi dengan media pembelajaran agar guru menjadi lebih kreatif dan profesional dalam membuat seluruh siswa berperan aktif selama proses pembelajaran untuk meningkatkan pemahaman konsep pada materi asam dan basa dalam memecahkan masalah.

Problem Based Learning merupakan suatu model pembelajar an yang dapat dikatakan strategi dimana siswa belajar melalui permasalahan-permasalahan praktis yang berhubungan dengan kehidupan nyata.

Penerapan model problem based learning berdasarkan hasil berbagai penelitian menunjukkan hasil yang poisitif. Misalnya, hasil penelitian Emalia (2017) menunjukkan bahwa keterampilan memecahkan masalah pada pembelajaran berbasis masalah ditunjukkan dengan adanya peningkatan nilai posttest setiap pertemuannya. Serta hasil penelitian Syaribuddin dkk (2016) menunjukkan bahwa pembelajaran dengan model problem based learning dengan media audio visual dapat meningkatkan kemampuan siswa dalam berpikir dalam memecahkan masalah.

Dalam penelitian ini, peneliti menggunakan model problem based learning disajikan dengan tipe masalah kinerja strategis dengan berbantuan multimedia pembelajaran larutan asam basa dan melihat pengaruh yang ditimbulkan terhadap keterampilan memecahkan masalah siswa. Hal ini dikarenakan pada kurikulum 2013 lebih ditekankan kepada pembelajaran yang berpusat pada siswa sehingga siswa mampu mengembangkan tingkat kognitifnya tanpa mengabaikan kemampuan afektifnya. Model problem based learning dengan tipe masalah kinerja strategis merupakan salah satu model yang menunjang terlaksananya pembelajaran kurikulum 2013 dengan baik.

\section{METODE PENELITIAN}

Pendekatan yang digunakan pada penelitian ini yang sesuai adalah pendekatan campuran (mix method) dengan menggunakan kedua data yaitu 
data kualitatif dan data kuantitatif. Pada tahapan penelitian campuran ini dipilih dari aspek waktu (sequential timing), mendahulukan aspek kualitatif dan diikuti aspek kuantitatif yaitu jenis model sequential exploratory (model urutan penemuan), dengan data kuantitatif lebih dominan dari pada data kualitatif.

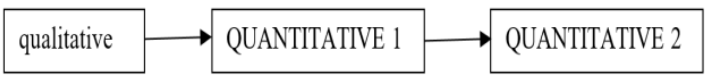

\section{Gambar 1 Desain Penelitian Mixed Method- Sequential Explanatory}

Penelitian ini dilakukan di SMA Islam AlFalah Kota Jambi siswa kelas XI MIA SMA Islam Al-Falah Kota Jambi pada tahun ajaran 2017/2018 yang terdiri atas tiga kelas.

Tabel 1 Jenis Data, Kegiatan, Sumber Data, Teknik Pengumpulan Data dan Validasi

\begin{tabular}{|l|l|l|l|l|l|}
\hline Jenis Data & Kegiatan & $\begin{array}{l}\text { Sumber } \\
\text { Data }\end{array}$ & $\begin{array}{l}\text { Teknik } \\
\text { Pengumpulan Data }\end{array}$ & Instrumen & Validasi \\
\hline Kualitatif & $\begin{array}{l}\text { Survey awval } \\
\text { penelitian }\end{array}$ & $\begin{array}{l}\text { Siswa } \\
\text { dan } \\
\text { guru }\end{array}$ & $\begin{array}{l}\text { Melakukan } \\
\text { wawancara } \\
\text { mendalam }\end{array}$ & $\begin{array}{l}\text { Pedoman } \\
\text { wawancara }\end{array}$ & - \\
\cline { 2 - 6 } & $\begin{array}{l}\text { Keterlaksanaan } \\
\text { pembelajaran } \\
\text { oleh guru } \\
\text { dalam bentuk } \\
\text { tindakan } \\
\text { mengajar }\end{array}$ & Melakukan observasi & $\begin{array}{l}\text { Pedoman } \\
\text { observasi }\end{array}$ & $\begin{array}{l}\text { Validasi isi } \\
\text { (content } \\
\text { validity) }\end{array}$ \\
\hline Kuantitatif & $\begin{array}{l}\text { Tindakan } \\
\text { Belajar Siswa }\end{array}$ & Siswa & Melakukan observasi & $\begin{array}{l}\text { Pedoman } \\
\text { observasi }\end{array}$ & $\begin{array}{l}\text { Validasi isi } \\
\text { (content } \\
\text { validity) }\end{array}$ \\
\cline { 2 - 6 } & $\begin{array}{l}\text { Hasil Belajar } \\
\text { Siswa } \\
\text { (keterampilan } \\
\text { memecahkan } \\
\text { masalah) }\end{array}$ & Siswa & $\begin{array}{l}\text { Melakukan } \\
\text { keterampilan } \\
\text { memecahkan } \\
\text { masalah }\end{array}$ & $\begin{array}{l}\text { Soal tes } \\
\text { essay }\end{array}$ & $\begin{array}{l}\text { Validasi isi } \\
\text { (content } \\
\text { validity) }\end{array}$ \\
\hline
\end{tabular}

Dalam penelitian ini, peneliti menggunakan teknik analisa data Miles and Huberman. Aktivitas dalam analisis data, yaitu reduksi data, penyajian data, dan penarikan kesimpulan. Berdasarkan gambar dibawah ini terlihat bahwa, setelah peneliti melakukan pengumpulan data, maka peneliti melakukan antisipasi sebelum melakukan reduksi data.

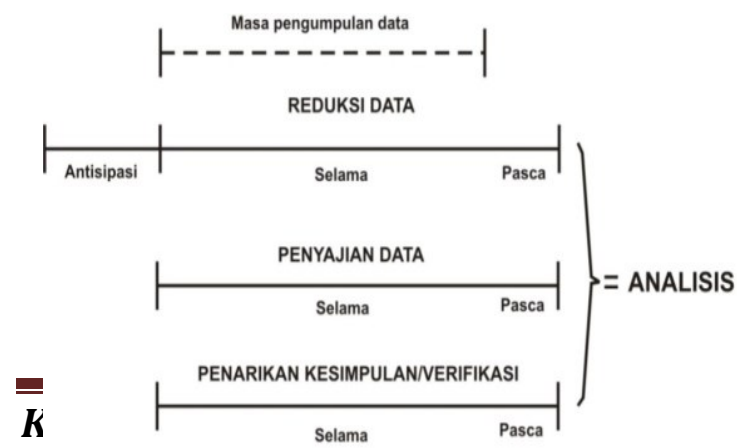

\section{Gambar 2 Analisis Data Kualitatif Miles and Huberman (1984)}

Setelah instrumen dikuantifikasi, analisa data jenis ini dapat menggunakan model analisa data deskriptif misalnya persentase rata-rata kelas. Sedangkan untuk analisa data inferensialnya menggunakan uji korelasi product moment (r). Dengan mencari korelasi antara keterlaksanaan model problem based learning pada tindakan siswa yang berisi indikator keterampilan memecahkan masalah dengan menggunakan rumus korelasi produk momen. Adapun rumusnya sebagai berikut:

$$
r_{x y}=\frac{N \Sigma x y-\left(\sum x\right)\left(\sum y\right)}{\sqrt{\left(N \Sigma x^{2}-\left(\sum x\right)^{2}\left(N \Sigma y^{2}-(\Sigma y)^{2}\right)\right.}}
$$

Keterangan:

$x=$ tindakan siswa dalam model problem based learning

$y=$ keterampilan memecahkan masalah

$r_{x y}=$ koefisien korelasi antara variable $x$ dan variable $y$

Dalam perhitungannya, peneliti menggunakan program microsoft excel. Setelah didapatkan nilai $r_{x y}$, selanjutnya nilai tersebut dapat diinterpretasikan dengan menggunakan pedoman dibawah ini.

Tabel 2 Pedoman Interpretasi Koefesien Korelasi

\begin{tabular}{|c|c|}
\hline $\begin{array}{c}\text { Interval } \\
\text { koefesien }\end{array}$ & $\begin{array}{c}\text { Tingkat } \\
\text { Hubungan }\end{array}$ \\
\hline $0,00-0,199$ & Sangat rendah \\
$0,20-0,399$ & Rendah \\
$0,40-0,599$ & Sedang \\
$0,60-0,799$ & Kuat \\
$0,80-1,000$ & Sangat kuat \\
\hline
\end{tabular}

Analisis lembar observasi keterlaksanaan model problem based learning siswa dilakukan dengan perhitungan skor yaitu masing-masing lembar observasi berisi 16 pernyataan dengan skor minimal 16 dan maksimal 60. Data keterlaksanaan model oleh siswa tersebut dianalisis dengan menjumlahkan skor dari masing-masing item pernyataan. Interpretasi skor tersebut adalah sebagai berikut: 
Skor minimum

Skor maksimum

Kategori kriteria

$$
\begin{aligned}
& : 1 \times 16=16 \\
& : 4 \times 16=64 \\
& : 4 \\
& : \frac{64-16}{4}=12
\end{aligned}
$$

Tabel 3.7 Kategori Keterlaksanaan Model Problem Based Learning oleh Siswa

\begin{tabular}{|c|c|}
\hline Skor & Kategori Keterlaksanaan Model \\
\hline $52-63$ & Sangat baik \\
\hline $40-51$ & Baik \\
\hline $28-39$ & Cukup baik \\
\hline $16-27$ & Kurang baik \\
\hline
\end{tabular}

\section{HASIL DAN PEMBAHASAN}

Penelitian ini dilakukan di SMA Islam AlFalah Kota Jambi pada semester genap di kelas XI MIA. Sampel yang digunakan hanya satu kelas untuk mendapat perlakuan dari pelaksanaan model problem based learning dan ditentukan dengan teknik purposive sampling, yaitu berdasarkan pertimbangan tertentu.

\section{Tindakan Mengajar Guru}

Dalam proses pembelajaran, keterlaksanaan model problem based learning yang dibantu dengan multimedia pembelajaran oleh guru diamati satu sampai dua orang observer berdasarkan langkah model setiap kali pertemuan. Adapun langkah-langkah dalam model problem based learning memiliki lima langkah yaitu orientasi masalah, mengorganisasikan siswa untuk belajar, mendukung kelompok investigasi, mengembangkan dan menyajikan data, menganalisis dan mengevaluasi proses pemecahan masalah.

Dari pertemuan 1 hingga pertemuan 3 dapat dikatakan bahwa perkembangan keterlaksanaan model problem based learning sudah terlaksana dan semakin baik dari pertemuan kedua dan ketiga.

\section{Tindakan Belajar Siswa}

Dalam proses pembelajaran, keterlaksanaan model problem based learning oleh siswa diamati oleh enam observer. Siswa dibagi menjadi tujuh kelompok yang masing-masing beranggotakan lima orang. Namun ada satu observer yang mengamati dua kelompok karena jumlah observer tidak sama dengan jumlah kelompok. Adapun langkah-langkah dalam model problem based learning memiliki lima langkah yaitu, orientasi masalah, mengorganisasikan siswa untuk belajar, membantu menyelidiki secara mandiri atau kelompok, mengembangkan dan menyajikan hasil kerja, serta menganalisis dan mengevaluasi hasil pemecahan masalah.

Pada pertemuan pertama secara keseluruhan dilihat dari skor hasil pengamatan lembar observasi siswa. Langkah-langkah model problem based learning dapat terlaksana seluruhnya dan sudah meningkat dari pertemuanpertemuan sebelumnya dilihat dari rata-rata skor.

\section{Analisis Substantive Tindakan Mengajar Guru dan Tindakan Belajar Siswa}

Analisis substantive yaitu melihat keterlaksanaan secara keseluruhan dari tindakan mengajar guru pertemuan 1-3 yang kemudian dihubungkan dengan tindakan belajar siswa dari setiap kegiatan pembelajarannya pertemuan 1-3.

\section{Pemecahan Masalah Kinerja Strategis oleh Siswa}

Masalah kinerja strategis merupakan jenis masalah yang dipilih dan coba di selesaikan. Pada masalah kinerja strategis komponen kasus dapat berupa masalah atau pengalaman sebelumnya. Serta siswa harus memiliki kemampuan kognitif dapat menyelesaikan masalah yang ada menggunakan skema masalah, menganalogikannya, serta membuat simulasi.

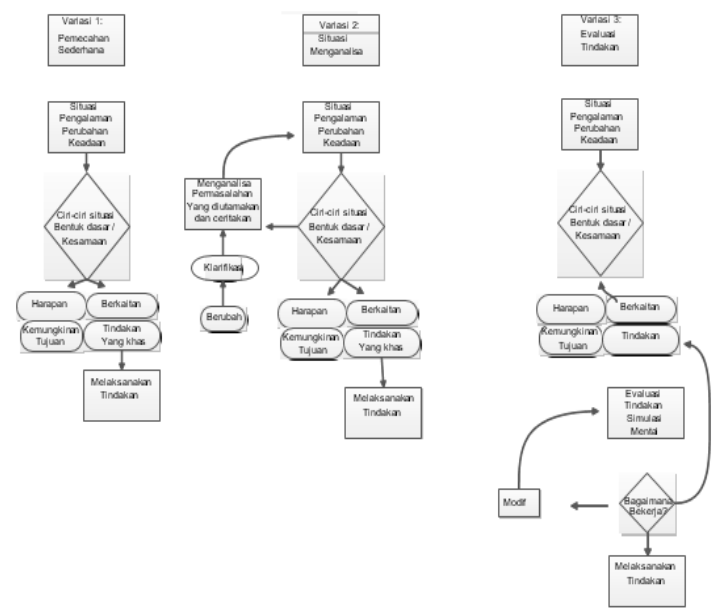

Gambar 3 Variasi-variasi Penyelesaian Masalah Kinerja Strategis

Ini merupakan bagan variasi-variasi penyelesaian masalah kinerja strategis dimana pada bagan $1 /$ variasi 1 , penyelesaian masalahnya 
masih cukup simpel. Jadi kemungkinan kemampuan kognitif yang ditunjukkan oleh siswa juga sedikit. Pada bagian kedua atau variasi 2 , bentuk penyelesaian masalahnya lebih komplek. Begitu juga pada bagian ketiga atau variasi 3. Apabila siswa menjawab soal menggunakan variasi yang ke 3, maka semua kemampuan yang dibutuhkan dalam menyelesaikan masalah kinerja strategis ini akan muncul (Jonnasen D, 2011).

Tabel 3 Persentase Hasil Kemampuan Memecahkan Masalah Siswa menurut Alur Penyelesaian Kinerja Strategis

\begin{tabular}{c|c|c|c|c|}
$\begin{array}{c}\text { Alur pemecahan } \\
\text { masalah }\end{array}$ & $\begin{array}{c}\text { Tes pertemuan } \\
1\end{array}$ & $\begin{array}{c}\text { Tes pertemuan } \\
2\end{array}$ & $\begin{array}{c}\text { Tes pertemuan } \\
3\end{array}$ & Tes ulangan \\
\hline Variasi 1 & $27.93 \%$ & $5.00 \%$ & $0.41 \%$ & - \\
\hline Variasi 2 & $72.05 \%$ & $84.24 \%$ & $48.89 \%$ & $27.42 \%$ \\
\hline Variasi 3 & - & $10.75 \%$ & $50.69 \%$ & $72.55 \%$ \\
\hline
\end{tabular}

Pada pertemuan pertama, siswa lebih cenderung menyelesaikan masalah pada variasi 2 yaitu $72,05 \%$ dan variasi 1 yaitu $27,93 \%$, hal ini dikarenakan siswa belum mampu berpikir menurut jenis masalah yang digunakan. Siswa juga belum terbiasa dengan jenis masalah yang digunakan sehingga siswa cenderung menjawab soal dengan jawaban yang singkat. Ini berarti kemampuan kognitif yang ditunjukkan oleh siswa masih sedikit.

Pada pertemuan kedua, siswa masih cenderung menyelesaikan masalah pada variasi 2 yaitu $84,24 \%$, namun untuk pertemuan kedua ini mengalami peningkatan yaitu $10,75 \%$ siswa mampu menjawab soal dengan variasi 3 dan hanya $5,00 \%$ siswa menjawab soal dengan variasi 1.

Pada pertemuan ketiga, siswa sudah mengalami peningkatan dimana siswa lebih cenderung menyelesaikan masalah dengan variasi 3 yaitu 50,69, sedangkan pada variasi 2 yaitu $48,89 \%$ dan untuk variasi 1 hanya $0,41 \%$. Dan untuk ulangan, siswa hampir keseluruhan menyelesaikan masalah dengan variasi 3 yaitu $72,55 \%$ dan variasi 2 yaitu $27,42 \%$ ini membuktikan bahwa ada peningkatan berpikir siswa dalam memecahkan suatu masalah dan kemampuan kognitif yang dibutuhkan dalam memecahkan masalah akan muncul.

\section{Keterampilan Memecahkan Masalah Siswa}

Keterampilan memecahkan masalah siswa diperoleh dari posttest setiap pertemuan dan ulangan harian diakhir pertemuan. Adapun skor yang diperoleh berdasarkan jawaban masalah alur kinerja strategis dan poin dari indikator keterampilan memecahkan masalah itu sendiri.

Tabel 4 Hasil Skor Rata-rata dan Persentase Kemampuan Memcahkan Masalah

\begin{tabular}{|c|c|c|c|c|}
\hline Penilaian & $\begin{array}{c}\text { Tes pertemuan } \\
1\end{array}$ & $\begin{array}{c}\text { Tes pertemuan } \\
2\end{array}$ & $\begin{array}{c}\text { Tes pettemuan } \\
3\end{array}$ & Tes ulangan \\
\hline Skor ratar-rata & 1.67 & 233 & 3.37 & 3.67 \\
\hline$\%$ & $41.79 \%$ & $58.21 \%$ & $84.29 \%$ & $91.79 \%$ \\
\hline
\end{tabular}

Persentase rata-rata keterampilan memecahkan masalah pada pertemuan 1 terbilang sangat rendah yaitu $41,79 \%$. Hal ini dikarenakan siswa yang belum memahami bentuk penyelesaian soal jenis masalah kinerja strategis. Mereka baru menemui bentuk soal dan penyelesaian seperti itu yang mengaharuskan siswa menganalisis soal terlebih dahulu untuk memahami isi soal dan bagaimana cara menyelesaikan permasalahan yang ada dalam soal.

Kemudian persentase rata-rata keterampilan memecahkan masalah siswa pada pertemuan 2 sudah mengalami peningkatan yang lebih baik dari pada pertemuan 1 walaupun belum signifikan yaitu 58,21\%. Hal ini dikarenakan siswa sudah mulai mampu memahami soal-soal yang diberikan dan soal yang diberikan pun berkaitan dengan praktikum yang telah dilaksanakan pada pertemuan 2 , sehingga siswa mulai memahami secara perlahan alur dalam penyeselan soal jenis masalah kinerja strategis

Selanjutnya persentase rata-rata keterampilan memecahkan masalah siswa pada pertemuan 3 mengalami peningkatan yaitu $84,29 \%$. Hal ini dikarenakan siswa sudah mampu memahami soal-soal yang diberikan dan soal yang diberikan pun masih berkaitan dengan praktikum yang telah dilaksanakan pada pertemuan 3 dan sudah munculnya kemampuan kognitif siswa dalam penyelesaian masalah kinerja strategis. Sehingga untuk persentase rata-rata keterampilan memecahkan masalah siswa saat ulangan juga mengalami peningkatan dari hasil posttest pertama 3 yaitu $91,79 \%$. 
Jadi secara keseluruhan keterampilan memecahkan masalah siswa perlahan meningkat meskipun tidak menunjukkan peningkatan tinggi.

\section{Analisis Korelasional}

Hubungan yang akan dilihat adalah keterlaksanaan model problem based learning berbantuan multimedia pembelajaran larutan asam basa dengan keterampilan memecahkan masalah siswa. Uji yang dilakukan dengan mencari korelasi menggunakan metode pearson atau sering disebut produk momen antara keterlaksanaan model problem based learning berbantuan multimedia pembelajaran asam basa dengan keterampilan memecahkan masalah siswa. Dari perhitungan koefisien korelasi (r) dari kedua data tersebut, diperoleh nilai $(\mathrm{r})=$ 0,43 . Berdasarkan tabel pedoman interpretasi koefisien korelasi (tabel 3.6) nilai (r) 0,43 berada pada interval 0,40-0,599 (Sugiyono, 2014), dengan demikian hubungan antara keterlaksanaan model pembelajaran problem based learning berbantuan multimedia pembelajaran larutan asam basa dengan keterampilan memecahkan masalah siswa pada penelitian ini memiliki tingkat hubungan yang sedang.

\section{KESIMPULAN}

Keterlaksanaan model problem based learning berbantuan multimedia pembelajaran larutan asam basa di kelas XI SMA Islam AlFalah Kota Jambi terlaksana dengan baik, ditunjukkan dengan peningkatan hasil presentasi keterlaksanaan oleh siswa pada setiap pertemuan. Selain itu, terdapat korelasi keterlaksanaan model problem based learning berbantuan multimedia pembelajaran larutan asam basa dengan keterampilan memecahkan masalah siswa dengan nilai $r_{x y}=0,43$ dengan kategori hubungan yang sedang.

\section{REFERENSI}

Abdul, Madjid. 2006. Perencanaan Pembelajaran. Bandung: Remaja Rosdakarya.

Abdur, Rahman A, 2013, Pembelajaran Berbasis Masalah dalam Matematika. Malang: Universitas Negeri Malang.

Amri, Sofan. 2013. Pengembangan dan Model Pembelajaran dalam Kurikulum 2013. Jakarta: Prestasi Pustakanya.
Arends, Richard I, 2004. Classroom Instruction and Management. New York: Mc-Graw Hill.

Arsyad, A. 2010. Media Pembelajaran. Jakarta: Raja Grafindo Persada.

Baharuddin, dan Esa, N. W. 2010. Teori Belajar \& Pembelajaran. Jogjakarta: Ar-Ruzz Media.

Creswell, John W. 1994. Reseacrh Design: Qualitative and Quantitative Approach. California: Sage Publication.

Daryanto. 2016. Pembelajaran Abad 21. Malang: Gava Media.

Dimyati dan Mudjiono. 2006. Belajar dan Pembelajaran. Jakarta: PT. Rineka Cipta.

Graaff, E.D. \& Kolmos, A. 2003. Characteristics of Problem-Based Learning. International Journal of Engineering Education. Volume 19 , No. 5 , pp. $657-662$.

Hamalik, Oemar. 2001. Proses Belajar Mengajar. Jakarta: Bumi Aksara.

Hofstetter, Fred T. 2001. Multimedia Literacy Third Edition. New York: Mc Graw Hill International Edition.

Hosnan, M. 2014. Pendekatan Saintifik dan Kontekstual dalam Pembelajaran Abad 21. Bogor: Ghalia Indonesia.

Isjoni. 2007. Cooperative Learning. Bandung: Alfabeta.

Jonassen, D. 2011. Learning To Solve Problems. New York and London: Routledge.

Jonassen, D. \& Hung, W. 2008. All Problems are Not Equal: Implications for Problem-Based Learning. Interdisciplinary Journal of Problem Based Learning. Volume 2, No. 2 pp. 6-8.

Memnun, Dillek Sezgin, dkk. 2012. A Research On The Mathematical Problem Solving Beliefs Of Mathematics, Sience and Elemantry Pre-Service. Teachers In Turkey In Terms Of Humanities and Social Sience. 24 (2): 173.

Ngalimun. 2014. Strategi dan Model Pembelajaran. Yogyakarta: Aswaja Pessindo.

Polya, G. 1971. How to Solve It: A New Aspect of Mathematical Method (Second ed.). New Jersey: Prentice Hall Inc.

Putra, SR. 2013. Desain Belajar Mengajar Kreatif Berbasis Sains. Yogyakarta: DIVA Press. 
Rusman. 2011. Model-model Pembelajaran: Mengembangkan Profesionalisme. Jakarta: PT. Rajagrafindo Persada.

Rustaman. 2005. Pengembangan Kompetensi (Pengetahuan, Ketrampilan, Sikap, dan Nilai) Melalui Kegiatan Praktikum Biologi. Bandung: Penelitian Jurusan Pendidikan Biologi FPMIPA UPI Bandung.

Sagala, S. 2013. Konsep dan Makna Pembelajaran. Bandung: Alfabeta.

Sani, Abdullah R., 2014. Pembelajaran Saintifik untuk Implementasi Kurikulum 2013. Jakarta: Bumi Aksara.

Sanjaya, Wina. 2008. Strategi Pembelajaran Berorientasi Standar Proses Pendidikan. Jakarta: Kencana Prenada Media Group.

Slameto. 2003. Belajar dan Faktor-faktor Yang Mempengaruhinya. Jakarta: Rineka Cipta.

Sternberg J. R, \& Grigorenko L. E., 2010, Mengajar kecerdasan sukses. Yogyakarta: Pustaka Pelajar.

Sudjana, N. 2005. Dasar-dasar Proses Belajar Mengajar. Jakarta: Algesindo.

Sugiyono, 2014, Metodologi Penelitian Pendidikan: Metode Penelitian Kualitatif dan Kuantitatif dan $R \& D$. Bandung: Alfabeta.

Sukardjo. 2009. Kimia SMA/MA Kelas XI. Jakarta: Bina Aksara.

Suprijono, A. 2009. Cooperative Learning. Surabaya: Pustaka Pelajar.

Sutirman. 2013. Media dan Model-model Pembelajaran Inovatif. Yogyakarta: Graha Ilmu.

Sutrisno. 2006. Pengantar Pembelajaran Inovatif. Jakarta: Gaung Persada Press Jakarta.

Syah, M. 2012. Psikologi Belajar. Jakarta: Raja Grafindo Persada.

Trianto. 2007. Model-Model Pembelajaran Inovatif Berorientasi Konstruktivistik. Jakarta: Prestasi Pustaka.

Wiyani, N. A. 2013. Desain Pembelajaran Pendidikan. Yogjakarta: Ar-Ruzz Media. 